\title{
A Comparison of Strategies for Estimation of Ultrafine Particle Number Concentrations in Urban Air Pollution Monitoring Networks
}

\author{
Matteo Reggente ${ }^{a^{*} 1}$, Jan Peters ${ }^{a}$, Jan Theunis ${ }^{a}$, Martine Van Poppel ${ }^{a}$, Michael Rademaker ${ }^{b}$, \\ Bernard De Baets ${ }^{b}$, Prashant Kumar ${ }^{c, d}$ \\ ${ }^{a}$ VITO, Flemish Institute for Technological Research, Boeretang 200, B-2400 Mol, Belgium \\ ${ }^{b}$ Department of Mathematical Modelling, Statistics and Bioinformatics, Ghent University, \\ Coupure links 653, 9000 GENT, Belgium \\ ${ }^{c}$ Department of Civil and Environmental Engineering, Faculty of Engineering and Physical \\ Science (FEPS), University of Surrey, GU2 7XH, United Kingdom \\ ${ }^{d}$ Environmental Flow (EnFlo) Research Centre, FEPS, University of Surrey, GU2 7XH, United \\ Kingdom
}

\begin{abstract}
We propose three estimation strategies (local, remote and mixed) for ultrafine particles (UFP) at three sites in an urban air pollution monitoring network. Estimates are obtained through Gaussian process regression based on concentrations of gaseous pollutants (NOx, $\mathrm{O}_{3}, \mathrm{CO}$ ) and UFP. As local strategy, we use local measurements of gaseous pollutants (local covariates) to estimate UFP at the same site. As remote strategy, we use measurements of gaseous pollutants and UFP from two independent sites (remote covariates) to estimate UFP at a third site. As mixed strategy, we use local and remote covariates to estimate UFP. The results suggest: UFP can be estimated with good accuracy based on NOx measurements at the same location; it is possible to estimate UFP at one location based on measurements of NOx or UFP at two remote locations; the addition of remote UFP to local NOx, $\mathrm{O}_{3}$ or $\mathrm{CO}$ measurements improves models' performance.
\end{abstract}

\section{Capsule abstract:}

UFP can be estimated with good accuracy at one location based on NOx measurements at the same location and based on measurements of NOx or UFP at two remote locations.

Key words: Ultrafine particles estimation; urban air pollution; pollution monitoring network; Gaussian process regression; statistical modelling.

\footnotetext{
* Corresponding author. E-mail address: reggente@gmail.com (Matteo Reggente).

${ }^{1}$ Present address: Atmospheric Particle Research Laboratory, Ecole Polytechnique Fédérale de Lausanne (EPFL), CH-1015 Lausanne, Switzerland. Tel: +41 216936331.
}

Cite this article as: Reggente, M., Peters, J., Theunis, J., Poppel, M.V, Rademaker, M., De Baets, B., Kumar, P., 2015. A comparison of strategies for estimation of ultrafine particle number concentrations in urban air pollution monitoring networks. Environmental Pollution 199, 209-218. Online link: doi:10.1016/j.envpol.2015.01.034 


\section{Introduction}

Exposure to traffic-related pollution, especially UFP and nitrogen oxides (NOx), is of great concern in urban environments because of their adverse impact on human health (Hong et al., 2002; de Hartog et al., 2003; Atkinson et al., 2010; Jacobs et al., 2010; Bos et al., 2011; Kumar et al., 2011a; Kumar et al., 2014).

UFP are commonly defined as particles having a diameter of less than $100 \mathrm{~nm}$ (Morawska et al., 1998), and the consensus is that these particles contribute most (around 80\%) of the total particle number concentration (PNC) (Heal et al., 2012; Kumar et al., 2011b; Morawska et al., 2008; Charron and Harrison, 2003), whereas their corresponding mass accounts for less than 20\% of the total particle mass concentration (Kittelson, 1998). UFP can be classified into the "nucleation", "Aitken" and "accumulation" modes. In terms of size ranges, the nucleation, Aitken and accumulation modes typically encompass 1-30, 20-100 and 30-300 nm, respectively. Particles with a diameter below $30 \mathrm{~nm}$ contain nearly $30 \%$ of total PNC (Morawska et al., 2008; Kumar et al., 2010).

Road vehicle emissions in polluted urban environments can contribute up to $90 \%$ of the total PNC (Kumar et al., 2010; Pey et al., 2009). The UFP along the roadside show an association with the vehicle flow characteristics. For instance, increasing vehicle speed increases the emissions of UFP (Kittelson et al., 2004). Among the road vehicles, diesel engines dominate road traffic emission of UFP, and heavy duty vehicles have an average factor of magnitude of two with respect to the light duty engine (Beddows and Harrison, 2008).

UFP vary spatially between the sources and the receptors living or travelling close to the roads (Kumar et al., 2014). This variation depends on many factors such as source type and strength, meteorological and dilution conditions, location geometry and transformation processes, among

Cite this article as: Reggente, M., Peters, J., Theunis, J., Poppel, M.V, Rademaker, M., De Baets, B., Kumar, P., 2015. A comparison of strategies for estimation of ultrafine particle number concentrations in urban air pollution monitoring networks. Environmental Pollution 199, 209-218. Online link: doi:10.1016/j.envpol.2015.01.034 
others (Heal et al., 2012; Goel and Kumar, 2014).

Currently there is no limit value to control ambient UFP. Consequently, there are not many UFP monitors deployed as part of the governmental monitoring stations. On the other hand, NOx, ozone $\left(\mathrm{O}_{3}\right)$ and carbon monoxide (CO) are regulated pollutants (Directive 2008/50/EC) and their monitors are spread all over Europe. Nitric oxide $(\mathrm{NO})$ and nitrogen dioxide $\left(\mathrm{NO}_{2}\right)$ together make NOx. Emissions of NOx are associated with all types of high-temperature combustion, but similar to UFP, their most important sources in urban areas remain road vehicles (Westmoreland et al., 2007; Alvarez et al., 2008; Kumar and Imam, 2013).

The dispersion modelling of pollutants mostly fits into two categories: deterministic and statistical. Deterministic dispersion models provide a link between theory and measurements and account for source dynamics and physico-chemical processes explicitly (Holmes and Morawska, 2006). A drawback of these models is that they need detailed information (e.g. boundary conditions), which is not always available. Statistical models do not describe the actual physical processes, but they treat the input data as random variables to derive a statistical description of the target distribution using a set of measurements. A few studies have used a statistical approach in the past (Hussein et al. 2006; Clifford et al., 2011; Mølgaard et al., 2012; Sabaliauskas et al. 2012; Reggente et al., 2014).

We employ a statistical modelling approach - Gaussian process (GP) regression - to estimate UFP in an urban air pollution monitoring network based on local and remote concentrations of NOx, $\mathrm{O}_{3}, \mathrm{CO}$ and UFP.

\section{Materials and Methods}

\subsection{Instrumentation}

We recorded UFP and gaseous pollutants for one month at a sampling frequency of 5 min and

Cite this article as: Reggente, M., Peters, J., Theunis, J., Poppel, M.V, Rademaker, M., De Baets, B., Kumar, P., 2015. A comparison of strategies for estimation of ultrafine particle number concentrations in urban air pollution monitoring networks. Environmental Pollution 199, 209-218. Online link: doi:10.1016/j.envpol.2015.01.034 
then averaged on a half-hourly basis.

Measurements of UFP were obtained using the GRIMM Nano-Check model 1.320. The NanoCheck can count total PNCs between 25 and $300 \mathrm{~nm}$, and provides the mean diameter of the measured size range.

Chemiluminescence (EN 14211), ultraviolet photometry (EN 14625) and non-dispersive infrared (EN14626) analysers (Air-pointer) were used to measure $\mathrm{NOx}, \mathrm{CO}$ and $\mathrm{O}_{3}$, respectively. The lowest detectable concentration was $1 \mu \mathrm{g} \mathrm{m} \mathrm{m}^{-3}$ for $\mathrm{NOx}$ and $\mathrm{O}_{3}$, and $50 \mu \mathrm{g} \mathrm{m}^{-3}$ for $\mathrm{CO}$.

Vehicle counts were recorded in four categories (cars, vans, small and big trucks/buses) using double inductive loop detectors at sites 1 and 3; video counting was performed to obtain traffic data at site 2 (Table 1$)$.

Table 1: Description of the measurement sites.

\begin{tabular}{lllll}
\hline & $\begin{array}{l}\text { Distance from traffic } \\
(\mathrm{m})\end{array}$ & $\begin{array}{l}\text { Weekday traffic } \\
\text { volume (veh/day) }\end{array}$ & $\begin{array}{l}\text { Weekend traffic } \\
\text { volume (veh/day) }\end{array}$ & $\begin{array}{l}\text { Heavy duty vehicle } \\
\text { on weekday } \\
\text { (weekend) (\% total) }\end{array}$ \\
\hline Site 1 & $\sim 3$ & 5000 & 4000 & $5 \%(2 \%)$ \\
Site 2 & $\sim 2$ & 4000 & 3000 & $4 \%(2 \%)$ \\
Site 3 & $\sim 20-30$ & 37,000 & 25,000 & $7 \%(3 \%)$ \\
\hline
\end{tabular}

\subsection{Description of the sampling locations}

Measurements were carried out in the Borgerhout district $\left(51^{\circ} 13^{\prime} \mathrm{N}\right.$ and $\left.4^{\circ} 26^{\prime} \mathrm{E}\right)$ of Antwerp, Belgium. Borgerhout is a typical urban commercial and residential area with busy traffic. Measurements were carried out simultaneously for one month (12/02/2010-12/03/2010) at three different sites (Figure 1). Sites 1 and 2 were located in two street canyons with two traffic lanes and moderate levels of traffic. The monitoring devices were deployed in parking lots (few metres far from the traffic). Site 3 was located in a parking area $\sim 30 \mathrm{~m}$ far from a major access 
road with busy traffic intersections and four lanes (two in each direction) and $~ 200 \mathrm{~m}$ far from a highway.

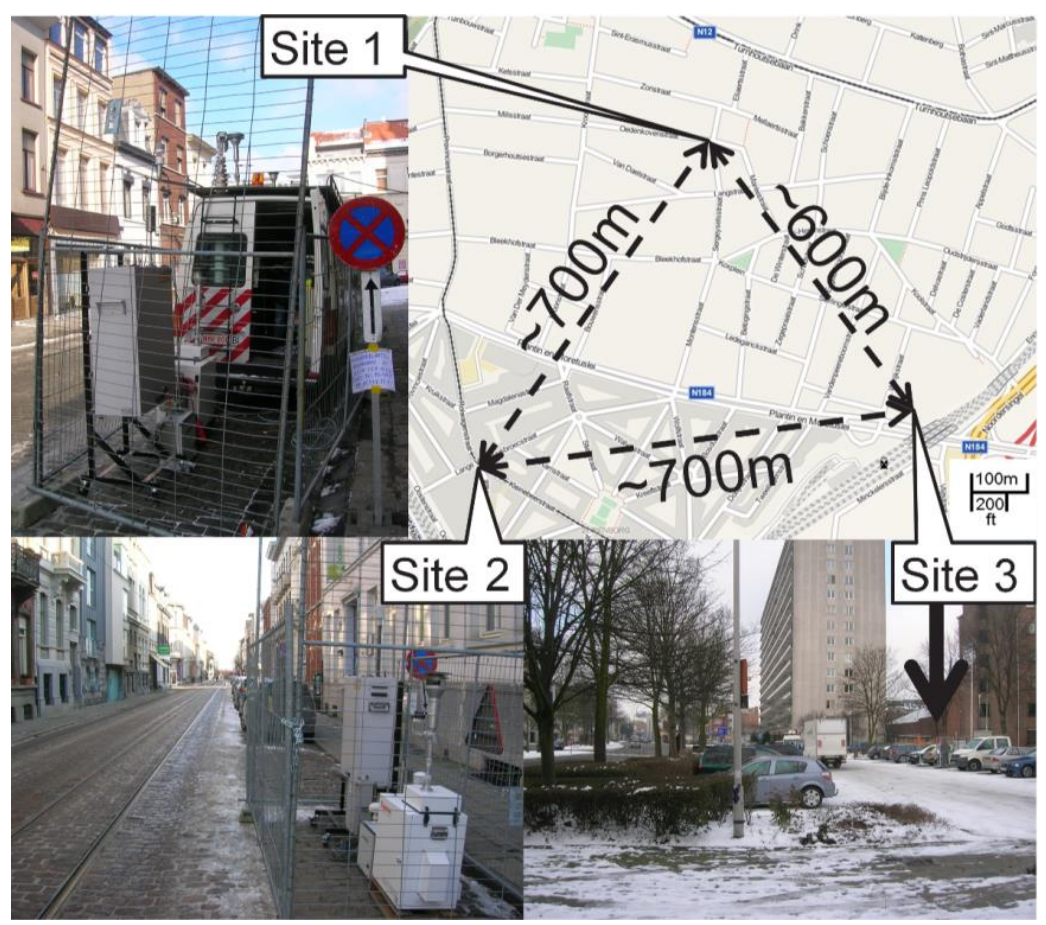

Figure 1: Map of the measurement sites (Antwerp, Belgium) and their distances from each other. The images show the deployed instrumentation at each site. The black arrow in the image of site 3 shows the location of the deployed monitors.

\subsection{Description of the model}

\subsubsection{Gaussian process regression}

We treat the estimation problem as a non-parametric regression problem, and solve it using Gaussian process (GP) regression.

Definition: A Gaussian process is a collection of random variables, any finite number of which have a joint Gaussian distribution (Rasmussen and Williams, 2006). We want to learn, from a set of measurements $(\mathcal{D})$ a function $f(\cdot)$ of the relationship existing between the set of covariates $\mathbf{x}$ Cite this article as: Reggente, M., Peters, J., Theunis, J., Poppel, M.V, Rademaker, M., De Baets, B., Kumar, P., 2015. A comparison of strategies for estimation of ultrafine particle number concentrations in urban air pollution monitoring networks. Environmental Pollution 199, 209-218. Online link: doi:10.1016/j.envpol.2015.01.034 
(NOx, $\mathrm{CO}, \mathrm{O}_{3}, \mathrm{UFP}$ ) and the target variable, UFP $(\boldsymbol{y})$, assuming that the observed data $\boldsymbol{y}$ is generated with Gaussian noise around the underlying function $f$

$$
\boldsymbol{y}=f(\mathbf{x})+\epsilon
$$

Because of the nature of the dataset used, we do not assume an independent noise, and the dependencies are modelled adding a noise term to the covariance function $\left(k_{\text {Noise }}\right)$. This method has been suggested by Rasmussen and Williams (2006) and by Murray-Smith and Girard (2001). Prior beliefs about the properties of the latent function are included in the mean $m(x)$ and covariance $k\left(\mathbf{x}, \mathbf{x}^{\prime}\right)$ functions. In order to estimate UFP based on data, we consider the joint Gaussian prior of the training observations $\boldsymbol{y}$ and the test outputs $\boldsymbol{f}_{*}$. The posterior distribution is obtained by conditioning the prior on the observed training outputs, such that the conditional distribution of $\boldsymbol{f}_{*}$ only contains those functions from the prior that are consistent with the training data

$$
p\left(\boldsymbol{f}_{*} \mid \mathbf{X}_{*}, \mathbf{X}, \mathbf{y}\right)=\mathcal{N}\left(\boldsymbol{\mu}_{*}, \boldsymbol{\Sigma}_{*}\right)
$$

where

$$
\begin{gathered}
\boldsymbol{\mu}_{*}=\boldsymbol{K}\left(\mathbf{X}_{*}, \mathbf{X}\right)\left[\boldsymbol{K}(\mathbf{X}, \mathbf{X})+\sigma_{n}^{2} \boldsymbol{I}\right]^{-1} \boldsymbol{y} \\
\boldsymbol{\Sigma}_{*}=\boldsymbol{K}\left(\mathbf{X}_{*}, \mathbf{X}_{*}\right)-\boldsymbol{K}\left(\mathbf{X}_{*}, \mathbf{X}\right)\left[\boldsymbol{K}(\mathbf{X}, \mathbf{X})+\sigma_{n}^{2} \boldsymbol{I}\right]^{-1} \boldsymbol{K}\left(\mathbf{X}, \mathbf{X}_{*}\right)
\end{gathered}
$$

are the posterior mean and the posterior variance, respectively. $\boldsymbol{K}$ is the covariance matrix, which is built from a covariance function (or kernel) $k\left(\mathbf{x}, \mathbf{x}^{\prime}\right)$. $\mathbf{X}$ and $\mathbf{X}_{*}$ are the matrices of the training and test inputs, respectively.

We have assumed that the mean of the GP prior is zero everywhere. At first glance, this could appear restrictive, but in practice it is not, because offsets and simple trends can be eliminated before modelling. The covariance function defines similarity between data points and it is chosen such that it reflects the prior beliefs about the function to be learned. Because UFP follow from a

Cite this article as: Reggente, M., Peters, J., Theunis, J., Poppel, M.V, Rademaker, M., De Baets, B., Kumar, P., 2015. A comparison of strategies for estimation of ultrafine particle number concentrations in urban air pollution monitoring networks. Environmental Pollution 199, 209-218. Online link: doi:10.1016/j.envpol.2015.01.034 
dynamic process, we have used a non-stationary kernel based on the addition of a linear $\left(k_{\text {Lin }}\right)$ and a rational quadratic kernel $\left(k_{R Q}\right)$. Moreover, we also include a noise term $\left(k_{\text {Noise }}\right)$ to take into account noise dependencies. The sum of kernels allows us to model the data as a superposition of independent functions representing different structures:

$$
\begin{gathered}
k\left(\mathbf{x}, \mathbf{x}^{\prime}\right)=k_{\text {Lin }}\left(\mathbf{x}, \mathbf{x}^{\prime}\right)+k_{R Q}\left(\mathbf{x}, \mathbf{x}^{\prime}\right)+k_{\text {Noise }}\left(\mathbf{x}, \mathbf{x}^{\prime}\right) \\
k_{\text {Lin }}\left(\mathbf{x}, \mathbf{x}^{\prime}\right)=\sigma_{0}^{2}+\left(\mathbf{x}^{\top} \mathbf{x}^{\prime}\right) \\
k_{R Q}\left(\mathbf{x}, \mathbf{x}^{\prime}\right)=\sigma^{2} \exp \left(1+\frac{\left\|\mathbf{x}-\mathbf{x}^{\prime}\right\|^{2}}{2 \alpha \ell^{2}}\right)^{-\alpha}
\end{gathered}
$$

For the noise model $\left(k_{\text {Noise }}\right)$ we use the sum of a squared exponential $\left(k_{S E}\right)$ contribution and an independent component

$$
k_{\text {Noise }}\left(\mathbf{x}, \mathbf{x}^{\prime}\right)=\sigma_{n}^{2} \exp \left(-\frac{\left\|\mathbf{x}-\mathbf{x}^{\prime}\right\|^{2}}{2 \ell_{n}^{2}}\right)^{2}+\sigma_{l}^{2} \delta_{i i^{\prime}}
$$

The hyperparameters are $\sigma_{0}$ (offset of the model), $\sigma, \sigma_{n}$ and $\sigma_{l}$ (magnitudes), $\alpha$ (relative weighing), $\ell$ and $\ell_{n}$ (length-scales). The reliability of the regression is dependent on how well we select the covariance function and therefore the covariance hyperparameters $\boldsymbol{\theta}$. The hyperparameters are selected by minimising the negative log marginal likelihood with respect to $\boldsymbol{\theta}$. Since by assumption the distribution of the data is Gaussian, the log marginal likelihood is:

$$
\mathcal{L}=\log p(\mathbf{y} \mid \mathbf{x}, \boldsymbol{\theta})=-\frac{1}{2} \mathbf{y}^{\top} k(\mathbf{X}, \mathbf{X})^{-1} \mathbf{y}-\frac{1}{2} \log |k(\mathbf{X}, \mathbf{X})|-\frac{n}{2} \log 2 \pi
$$

The values of the hyperparameters that optimize the marginal likelihood, are found using its partial derivative in conjunction with a numerical optimization routine based on conjugate gradients. We refer to Chapters 2 and 5 in Rasmussen and Williams (2006) for a detailed description of GP models.

The major limitation of GP regression is the computational complexity, since it requires matrix inversion, which has a complexity of $\mathcal{O}\left(n^{3}\right)$, where $n$ is the number of training data points. Cite this article as: Reggente, M., Peters, J., Theunis, J., Poppel, M.V, Rademaker, M., De Baets, B., Kumar, P., 2015. A comparison of strategies for estimation of ultrafine particle number concentrations in urban air pollution monitoring networks. Environmental Pollution 199, 209-218. Online link: doi:10.1016/j.envpol.2015.01.034 
Different solutions have been proposed to cope with this problem (e.g. Higdon, 1998; Rasmussen and Ghahramani, 2002; Snelson and Ghahramani, 2006). In this work, in the case of 5 min data, we have used the FITC approximation (Snelson and Ghahramani, 2006).

\subsubsection{Estimation strategies}

Figure 2 depicts the three different strategies that we have employed to estimate UFP at each site in the monitoring network. For the sake of brevity, we show only the estimation of UFP number concentration (target of the model) at site 1 (black dot) in each panel of Figure 2.

Considering the high cost of the pollutant monitors ( $\sim 10,000$ Euro), we have evaluated models that use covariates from only one monitor at each site. The inclusion of additional covariates requires the inclusion of one monitor for each covariate, increasing the costs of the instrumentation and maintenance.

Local estimation: At each site, we use local measurements of $\mathrm{NOx}, \mathrm{O}_{3}$ and $\mathrm{CO}$ (local covariates) to estimate UFP at the same site.

Remote estimation: In this strategy, we use either UFP or NOx measurements from two sites to estimate UFP at a third site. For this strategy, we evaluate the models for the cases in which UFP measurements are either included or not in the set of covariates.

Mixed estimation: In this strategy, we use combinations of local gaseous pollutants measurements (local covariates) and remote UFP or gaseous pollutants measurements (remote covariates) to estimate UFP at the target site. Also for this strategy, we evaluate the models for the cases in which remote UFP number concentration measurements are either included or not in the set of covariates.

Cite this article as: Reggente, M., Peters, J., Theunis, J., Poppel, M.V, Rademaker, M., De Baets, B., Kumar, P., 2015. A comparison of strategies for estimation of ultrafine particle number concentrations in urban air pollution monitoring networks. Environmental Pollution 199, 209-218. Online link: doi:10.1016/j.envpol.2015.01.034 


\section{Local Estimation Remote Estimation Mixed Estimation}

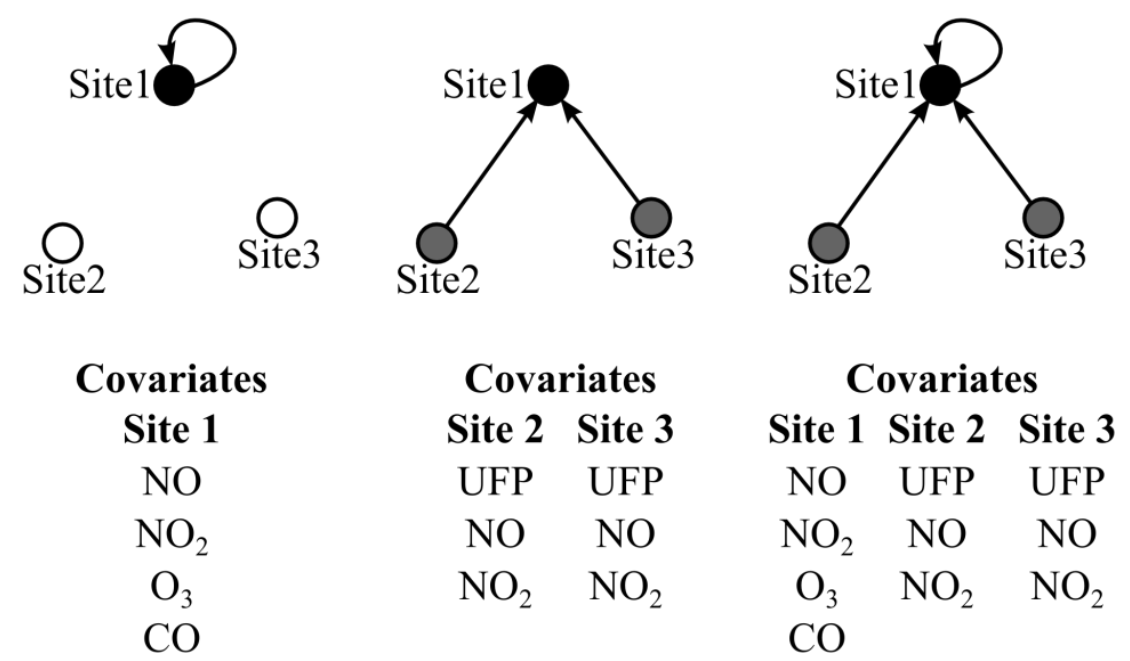

Figure 2: Estimation strategies and their set of covariates for: local estimation (left), remote estimation (middle), and mixed estimation (right). Black dots depict the site of the UFP estimation.

\subsection{Model evaluation}

In order to evaluate the model we have followed the steps suggested by Bennett et al. (2013). First of all, we have divided the dataset at each site into two disjoint datasets. The data collected during the first two weeks of the measurement campaign have been used as training set $\left(\mathcal{D}_{\text {train }}\right)$. The data collected during the third and fourth week of the measurement campaign have been used as unseen data to evaluate the proposed model $\left(\mathcal{D}_{\text {eval }}\right)$. At site 2 , the evaluation dataset is limited to 9 days due to monitor malfunctioning. In the second step, we have used the highest marginal likelihood (ML) to select the models that have at the same time a good fit and a low complexity. At this stage, we have compared models (at half hour resolution) based on the maximum length (14 days) of training. In the third step, we have evaluated the selected models 
in terms of their ability to estimate unseen measurements. We have used the $\mathrm{R}^{2}$ and RMSE metrics because their wide usage aids communication of the model performance.

\subsubsection{Marginal Likelihood (ML)}

The log marginal likelihood is

$$
\log p(\mathbf{y} \mid \mathbf{x}, \boldsymbol{\theta})=-\frac{1}{2} \mathbf{y}^{\top} k(\mathbf{X}, \mathbf{X})^{-1} \mathbf{y}-\frac{1}{2} \log |k(\mathbf{X}, \mathbf{X})|-\frac{n}{2} \log 2 \pi
$$

The first term gives a measure of the quality of the model fit. It is the only term that involves observed targets. The second term is a complexity penalty term, which measures and penalizes the complexity of the model. The third term is a log normalization term. Models with a higher ML should be preferred to models with a lower ML.

\subsubsection{Coefficient of determination $\left(R^{2}\right)$}

The coefficient of determination $\mathrm{R}^{2}$ indicates the fraction of variance of observations explained by the model:

$$
\mathrm{R}^{2}=1-\frac{\sum_{m=1}^{M}\left(y_{m}-y_{*}\right)^{2}}{\sum_{m=1}^{M}\left(y_{m}-\bar{y}\right)^{2}}
$$

where $y_{m}$ and $y_{*}$ are the measured and estimated UFP; $\bar{y}$ is the mean of the observed UFP; $M$ is the number of evaluation measurements.

\subsubsection{Root Mean Square Error (RMSE)}

The root mean square error (RMSE) is calculated as the difference between the measured UFP and the estimated ones:

$$
\mathrm{RMSE}=\sqrt{\frac{1}{M} \sum_{m=1}^{M}\left(y_{m}-y_{*}\right)^{2}}
$$

Cite this article as: Reggente, M., Peters, J., Theunis, J., Poppel, M.V, Rademaker, M., De Baets, B., Kumar, P., 2015. A comparison of strategies for estimation of ultrafine particle number concentrations in urban air pollution monitoring networks. Environmental Pollution 199, 209-218. Online link: doi:10.1016/j.envpol.2015.01.034 
where $y_{m}$ and $y_{*}$ are the measured and estimated UFP and $M$ is the number of evaluation measurements.

\section{Results and discussion}

In this section, first we present a statistical summary of UFP concentrations, diameters and gaseous pollutant concentrations recorded over the entire sampling period. Second, for each model strategy, we show the model selection results (based on ML). Third, we evaluate and discuss the performance of the selected GP models by comparing the estimated UFP with the measured ones. We conclude by assessing the models on different amounts of training data at half hour resolution and their performance at $5 \mathrm{~min}$ resolution. All the results are based on logtransformed and standardized data with zero mean and unit variance.

\subsection{Summary statistics}

Table 2 shows that the UFP concentrations are within the same range at all three sites, although traffic density at site 3 is almost one order of magnitude higher than that at the other two sites (Table 1). Dilution effects are leading to the lower UFP concentration at site 3 compared to what would have been expected from the traffic counts. The summary of data in Table 2 confirms that the traffic volume is not the only decisive factor in the variations of UFP. The distance from the moving traffic, the site morphology and dispersion conditions specific to individual sampling locations are also contributing factors (Kumar et al., 2014). These observations are also in agreement with the findings of Kumar et al. (2008), Buonanno et al. (2009), Kumar et al. (2009), Buonanno et al. (2011), Fujitani et al. (2012) and Peters et al. (2013).

The mean UFP diameters at the sites are also similar and vary between $48 \mathrm{~nm}$ (site 3) and $52 \mathrm{~nm}$ (site1), with the maximum values ranging between $80 \mathrm{~nm}$ (sites 2 and 3) and $96 \mathrm{~nm}$ (site 1).

Cite this article as: Reggente, M., Peters, J., Theunis, J., Poppel, M.V, Rademaker, M., De Baets, B., Kumar, P., 2015. A comparison of strategies for estimation of ultrafine particle number concentrations in urban air pollution monitoring networks. Environmental Pollution 199, 209-218. Online link: doi:10.1016/j.envpol.2015.01.034 
The NOx, $\mathrm{CO}$ and $\mathrm{O}_{3}$ concentrations (according to the medians and the inter-quartile ranges) are similar at all three sites. The higher traffic intensity at site 3 as compared to sites 1 and 2 is again probably offset by the larger distance to the traffic (Table 1) and resulting pollutant dilution.

Table 2: Summary statistics of UFP number concentrations measured at the three sites.

\begin{tabular}{|c|c|c|c|c|c|c|c|c|}
\hline & Variable & Mean & Std & Median & Min & Max & $\overline{\mathrm{Q} 1}$ & Q3 \\
\hline & $\operatorname{UFP}\left(\# \mathrm{~cm}^{-3}\right)$ & 22,810 & 12,934 & 20,628 & 1768 & 88,004 & 13,190 & 29,316 \\
\hline \multirow{5}{*}{ Site 1} & UFP diameter (nm) & 52 & 9 & 50 & 32 & 96 & 46 & 57 \\
\hline & $\mathrm{NO}\left(\mu \mathrm{g} \mathrm{m}^{-3}\right)$ & 57 & 69 & 36 & 0 & 571 & 14 & 70 \\
\hline & $\mathrm{NO} 2\left(\mu \mathrm{g} \mathrm{m}^{-3}\right)$ & 56 & 26 & 54 & 5 & 150 & 36 & 73 \\
\hline & $\mathrm{O} 3\left(\mu \mathrm{g} \mathrm{m}^{-3}\right)$ & 32 & 21 & 32 & 1 & 88 & 14 & 49 \\
\hline & $\mathrm{CO}\left(\mu \mathrm{g} \mathrm{m}^{-3}\right)$ & 435 & 220 & 376 & 84 & 1658 & 286 & 515 \\
\hline \multirow{6}{*}{ Site 2} & $\operatorname{UFP}\left(\# \mathrm{~cm}^{-3}\right)$ & 21,586 & 11,249 & 19,278 & 2168 & 80,355 & 13,866 & 27,486 \\
\hline & UFP diameter (nm) & 51 & 8 & 49 & 29 & 80 & 44 & 56 \\
\hline & $\mathrm{NO}\left(\mu \mathrm{g} \mathrm{m}^{-3}\right)$ & 78 & 80 & 53 & 1 & 716 & 29 & 97 \\
\hline & $\mathrm{NO} 2\left(\mu \mathrm{g} \mathrm{m}^{-3}\right)$ & 72 & 30 & 70 & 11 & 170 & 50 & 89 \\
\hline & $\mathrm{O} 3\left(\mu \mathrm{g} \mathrm{m}^{-3}\right)$ & 27 & 19 & 23 & 3 & 83 & 9 & 41 \\
\hline & $\mathrm{CO}\left(\mu \mathrm{g} \mathrm{m}^{-3}\right)$ & - & - & - & - & - & - & - \\
\hline \multirow{6}{*}{ Site 3} & $\operatorname{UFP}\left(\# \mathrm{~cm}^{-3}\right)$ & 23,219 & 14,129 & 19,518 & 2528 & 87,210 & 13,703 & 28,883 \\
\hline & UFP diameter (nm) & 48 & 8 & 46 & 28 & 80 & 42 & 53 \\
\hline & $\mathrm{NO}\left(\mu \mathrm{g} \mathrm{m}^{-3}\right)$ & 69 & 101 & 31 & 1 & 854 & 11 & 85 \\
\hline & $\mathrm{NO} 2\left(\mu \mathrm{g} \mathrm{m}^{-3}\right)$ & 62 & 33 & 57 & 7 & 218 & 37 & 82 \\
\hline & $\mathrm{O} 3\left(\mu \mathrm{g} \mathrm{m}^{-3}\right)$ & 30 & 21 & 26 & 1 & 91 & 10 & 47 \\
\hline & $\mathrm{CO}\left(\mu \mathrm{g} \mathrm{m}^{-3}\right)$ & 322 & 221 & 270 & 25 & 1606 & 164 & 403 \\
\hline
\end{tabular}

\subsection{Model selection and evaluation}

\subsubsection{Local estimation}

The ML metric (based on $\mathcal{D}_{\text {train }}$; Table 3) reveals that the models that use NOx as covariates $\left(\mathrm{GP}_{\mathrm{Sn}}\left(\mathrm{NOx}_{\mathrm{Sn}}\right), n=1, \ldots, 3\right.$ in bold $)$ outperform the models that use $\mathrm{O}_{3}\left(\mathrm{GP}_{\mathrm{Sn}}\left(\mathrm{O}_{\mathrm{Sn}}\right), n=1, \ldots 3\right)$ or $\mathrm{CO}$ as covariates $\left(\mathrm{GP}_{\mathrm{Sm}}\left(\mathrm{CO}_{\mathrm{Sm}}\right), m=1, \ldots, 2\right)$. Moreover, the results based on the unseen measurements $\left(\mathrm{R}^{2}\right.$ and RMSE metrics in Table 3) confirm that the selected models

Cite this article as: Reggente, M., Peters, J., Theunis, J., Poppel, M.V, Rademaker, M., De Baets, B., Kumar, P., 2015. A comparison of strategies for estimation of ultrafine particle number concentrations in urban air pollution monitoring networks. Environmental Pollution 199, 209-218. Online link: doi:10.1016/j.envpol.2015.01.034 
$\left(\mathrm{GP}_{\mathrm{Sn}}\left(\mathrm{NOx}_{\mathrm{Sn}}\right)\right)$ outperform the others, and they show a good correspondence between the modelled and the measured values. At all three sites, the models explain between $87 \%$ (site 2 ) and $90 \%$ (site 1$)$ of the variance.

These results are probably due to the strong correlation of UFP with NOx. More in detail, road vehicles are the major sources of UFP in urban environments (Kumar et al., 2014; Harrison et al., 2011; Pey et al., 2009). These vehicles also generate NO (from all types of combustion engines) and primary $\mathrm{NO}_{2}$ (especially from diesel cars equipped with after treatment technologies including oxidation catalysts) at the same time. Moreover, the Belgian car fleet presents a high share of diesel vehicles (64.3\%; Beckx et al., 2013), which have high emission of both UFP and NOx (Beddows and Harrison, 2008).

From Figure 3, we can observe that the model tends to underestimate high and low values of UFP at site 2 as opposed to underestimation of low values at site 3 . It should be emphasized that these deviations are not substantial, and the estimated distributions seem to describe the measurements well. In particular, the models do not tend to underestimate high concentrations. In summary: the GP models that use NOx as covariates outperform the models that use $\mathrm{CO}$ and $\mathrm{O}_{3}$ as covariates.

Table 3: Local estimation: evaluation of the models at half hour resolution and 14 days of training in terms of ML, $\mathrm{R}^{2}$ and RMSE. In bold are denoted the models with the highest ML.

\begin{tabular}{|c|c|c|c|c|c|c|}
\hline Target & Model & Local Covariates & $\mathrm{R}^{2}$ & RMSE & ML & $\begin{array}{l}\mathcal{D}_{\text {eval }} \\
\text { (days) }\end{array}$ \\
\hline \multirow{3}{*}{$\begin{array}{l}\text { UFP } \\
\text { Site } 1\end{array}$} & $\mathbf{G P}_{\mathrm{S} 1}\left(\mathrm{NOx}_{\mathrm{S} 1}\right)$ & $\mathrm{NO} / \mathrm{NO}_{2}$ & 0.90 & 0.35 & -115 & 14 \\
\hline & $\mathrm{GP}_{\mathrm{S} 1}\left(\mathrm{O} 3_{\mathrm{S} 1}\right)$ & $\mathrm{O}_{3}$ & 0.57 & 0.67 & -466 & 14 \\
\hline & $\mathrm{GP}_{\mathrm{S} 1}\left(\mathrm{CO}_{\mathrm{S} 1}\right)$ & $\mathrm{CO}$ & 0.55 & 0.67 & -511 & 14 \\
\hline \multirow{2}{*}{$\begin{array}{l}\text { UFP } \\
\text { Site } 2\end{array}$} & $\operatorname{GP}_{\mathrm{S} 2}\left(\mathbf{N O x}_{\mathrm{S} 2}\right)$ & $\mathrm{NO} / \mathrm{NO}_{2}$ & 0.87 & 0.45 & -168 & 9 \\
\hline & $\mathrm{GP}_{\mathrm{S} 2}\left(\mathrm{O} 3_{\mathrm{s} 2}\right)$ & $\mathrm{O}_{3}$ & 0.53 & 0.73 & -392 & 9 \\
\hline UFP & $G_{P_{S 3}}\left(N^{\left.N O x_{S 3}\right)}\right.$ & $\mathrm{NO} / \mathrm{NO}_{2}$ & 0.88 & 0.39 & -403 & 14 \\
\hline Site 3 & $\mathrm{GP}_{\mathrm{S} 3}\left(\mathrm{O}_{\mathrm{S} 3}\right)$ & $\mathrm{O}_{3}$ & 0.65 & 0.62 & -520 & 14 \\
\hline
\end{tabular}



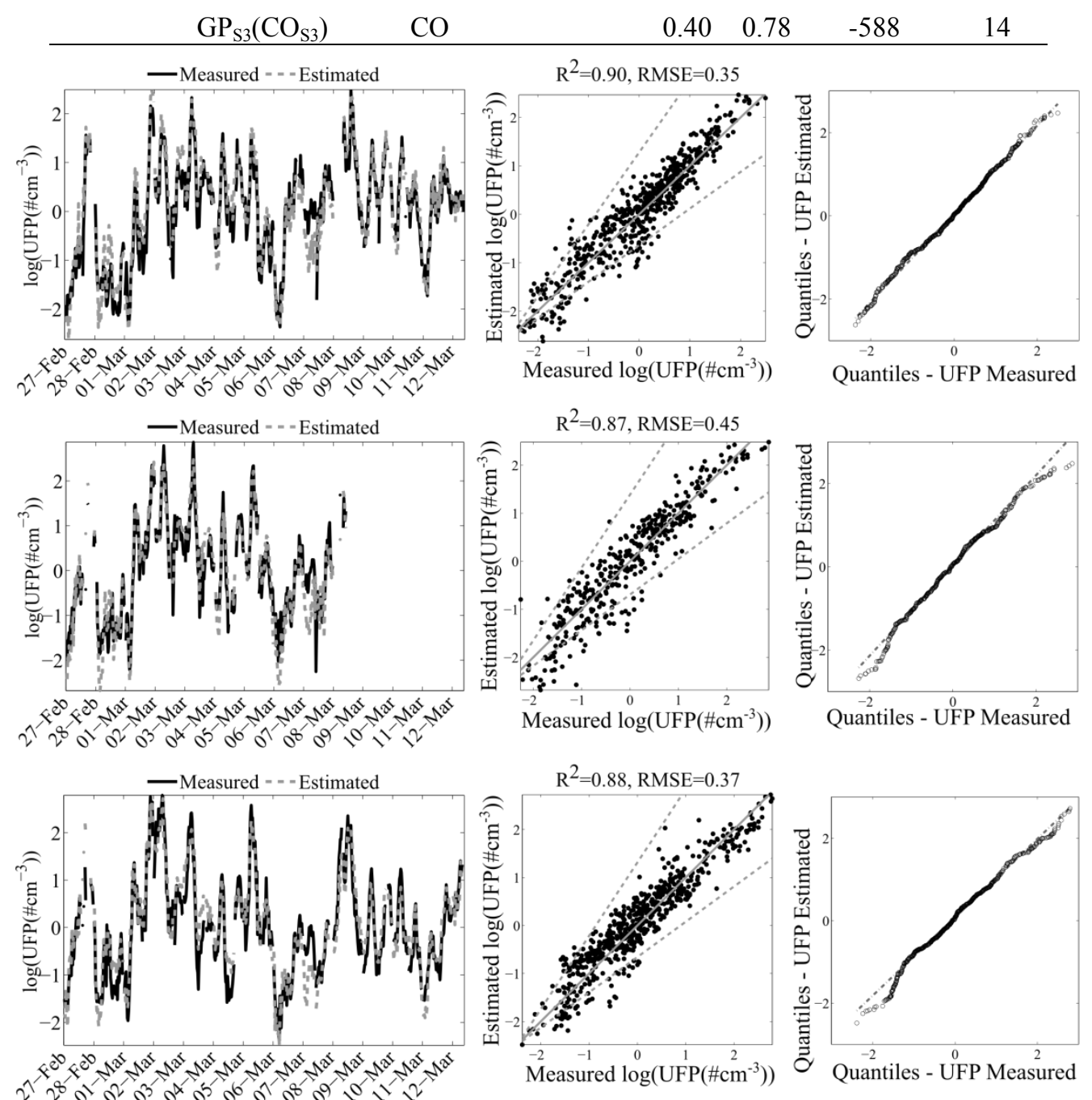

Figure 3: Local estimation. The left column shows the time series plots of the estimated and the measured UFP number concentrations. The dashed grey line is the estimated UFP number concentration and the black line is the measured UFP number concentration relative to the evaluation period $\left(\mathcal{D}_{\text {eval }}\right)$. The middle column shows the scatterplots, $\mathrm{R}^{2}$ and RMSE between the estimated and measured UFP number concentrations. The grey lines have slope 1 and an intercept of 0 (ideal case, when the estimated and measured values are equal). The dashed grey lines delimit the FAC2 area. The right column shows the QQ plots between the estimated and measured UFP number concentrations. The top row refers to site 1, the middle row refers to site 
2 and the bottom row refers to site 3.

\subsubsection{Remote estimation}

Tables 4 and 5 show the results obtained in the remote estimation configuration. In Table 4, the evaluation refers to those models that use UFP data recorded at any of the two sites (remote covariates) to estimate UFP at a third site. In Table 5, the evaluation refers to those models that use NOx measurements as remote covariates to estimate UFP at a third site.

The models selected in the training phase (higher ML), at all three sites, are the ones that use both UFP measurements recorded at the other two sites (in bold in Table 4). Moreover, the results based on the unseen measurements ( $\mathrm{R}^{2}$ and RMSE metrics in Tables 4 and 5) confirm that the selected models outperform the others. Those models explain between $69 \%$ (site 1) and $87 \%$ (site 2) of the variance.

Comparison of these results with those obtained in the local estimation configuration (Tables 3) shows that the model performances at sites 1 and 3 are weaker compared with the local estimation and similar at site 2 . The weaker performance at two sites can be explained by the absence of local covariates.

Table 4: Remote estimation based on UFP covariates: evaluation of the models at half hour resolution and 14 days of training in terms of ML, $\mathrm{R}^{2}$ and RMSE. In bold are denoted the models with the highest ML.

\begin{tabular}{|c|c|c|c|c|c|c|c|c|}
\hline \multirow[b]{2}{*}{ Target } & \multirow[b]{2}{*}{ Model } & \multicolumn{3}{|c|}{ Remote Covariates } & \multirow[b]{2}{*}{$\mathrm{R}^{2}$} & \multirow[b]{2}{*}{ RMSE } & \multirow[b]{2}{*}{ ML } & \multirow[b]{2}{*}{$\begin{array}{l}\mathcal{D}_{\text {eval }} \\
\text { (days) }\end{array}$} \\
\hline & & $\begin{array}{l}\text { UFP } \\
\text { Site } 1\end{array}$ & $\begin{array}{l}\text { UFP } \\
\text { Site } 2\end{array}$ & $\begin{array}{l}\text { UFP } \\
\text { Site } 3\end{array}$ & & & & \\
\hline \multirow{3}{*}{$\begin{array}{l}\text { UFP } \\
\text { Site } 1\end{array}$} & $\mathrm{GP}_{\mathrm{S} 1}\left(\mathrm{UFP}_{\mathrm{S} 2}, \mathrm{UFP}_{\mathrm{S} 3}\right)$ & & $\mathbf{X}$ & $\mathbf{X}$ & 0.69 & 0.58 & -398 & 14 \\
\hline & $\mathrm{GP}_{\mathrm{S} 1}\left(\mathrm{UFP}_{\mathrm{S} 2}\right)$ & & $\mathrm{X}$ & & 0.68 & 0.58 & -433 & 14 \\
\hline & $\mathrm{GP}_{\mathrm{S} 1}\left(\mathrm{UFP}_{\mathrm{S} 3}\right)$ & & & $\mathrm{X}$ & 0.58 & 0.65 & -557 & 14 \\
\hline \multirow{3}{*}{$\begin{array}{l}\text { UFP } \\
\text { Site } 2\end{array}$} & $\mathbf{G P}_{\mathbf{S} 2}\left(\mathrm{UFP}_{\mathrm{S} 1}, \mathbf{U F P}_{\mathrm{S} 3}\right)$ & $\mathbf{X}$ & & $\mathbf{X}$ & 0.87 & 0.35 & -190 & 14 \\
\hline & $\mathrm{GP}_{\mathrm{S} 2}\left(\mathrm{UFP}_{\mathrm{S} 1}\right)$ & $\mathrm{X}$ & & & 0.65 & 0.59 & -383 & 14 \\
\hline & $\mathrm{GP}_{\mathrm{S} 2}\left(\mathrm{UFP}_{\mathrm{S} 3}\right)$ & & & $\mathrm{X}$ & 0.82 & 0.42 & -345 & 14 \\
\hline
\end{tabular}

Cite this article as: Reggente, M., Peters, J., Theunis, J., Poppel, M.V, Rademaker, M., De Baets, B., Kumar, P., 2015. A comparison of strategies for estimation of ultrafine particle number concentrations in urban air pollution monitoring networks. Environmental Pollution 199, 209-218. Online link: doi:10.1016/j.envpol.2015.01.034 


\begin{tabular}{llcccccc} 
& $\mathbf{G P}_{\mathrm{S3}}\left(\mathbf{U F P}_{\mathrm{S1}}, \mathbf{U F P}_{\mathbf{S 2}}\right)$ & $\mathbf{X}$ & $\mathbf{X}$ & $\mathbf{0 . 8 1}$ & $\mathbf{0 . 4 2}$ & $\mathbf{- 4 2 3}$ & $\mathbf{1 4}$ \\
$\mathrm{U}$ & $\mathrm{GP}_{\mathrm{S} 3}\left(\mathrm{UFP}_{\mathrm{S} 1}\right)$ & $\mathrm{X}$ & & 0.56 & 0.68 & -526 & 14 \\
& $\mathrm{GP}_{\mathrm{S} 3}\left(\mathrm{UFP}_{\mathrm{S} 2}\right)$ & & $\mathrm{X}$ & 0.80 & 0.45 & -442 & 14 \\
\hline
\end{tabular}

Table 5: Remote estimation based on $\mathrm{NO} / \mathrm{NO}_{2}$ covariates: evaluation of the models at half hour resolution and 14 days of training in terms of ML, $\mathrm{R}^{2}$ and RMSE.

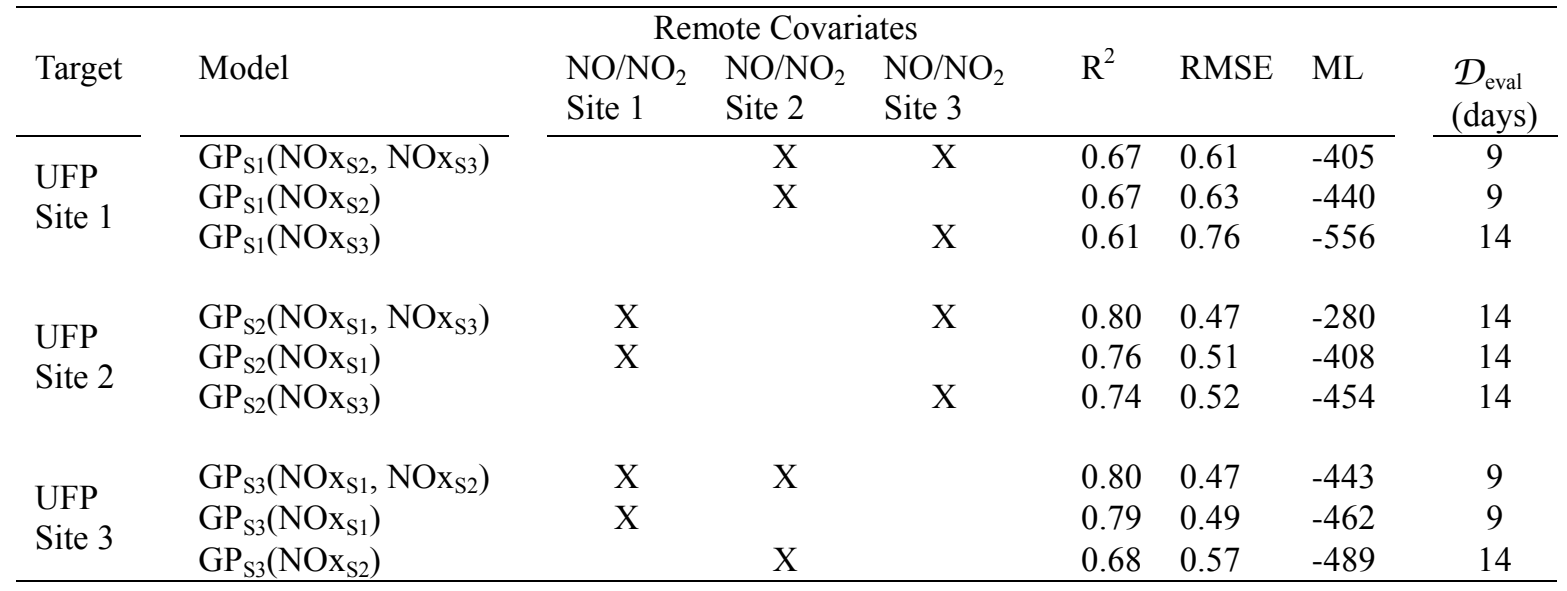

In the case of models that use NOx measurements (Table 5) recorded at two sites (remote covariates) to estimate UFP at a third site, the best models are obtained using remote NOx measurements from two sites simultaneously. Those models have a similar performance, at sites 1 and 3, and worse, at site 2, than that of models that use UFP as covariates, and they explain between $67 \%$ (site 1) and $80 \%$ (sites 2 and 3 ) of the variance.

We would like to point out that caution has to be taken when comparing the model performances reported in Tables 4 and 5. At site 2, gaseous measurements are limited to 9 days due to monitor malfunctioning (Section 2.4). Therefore, the performance of the models, which use NOx covariates recorded at site 2 , are computed using a shorter dataset $\left(\mathcal{D}_{\text {eval }}\right)$ than the others ( 9 days instead of 14 days).

Cite this article as: Reggente, M., Peters, J., Theunis, J., Poppel, M.V, Rademaker, M., De Baets, B., Kumar, P., 2015. A comparison of strategies for estimation of ultrafine particle number concentrations in urban air pollution monitoring networks. Environmental Pollution 199, 209-218. Online link: doi:10.1016/j.envpol.2015.01.034 

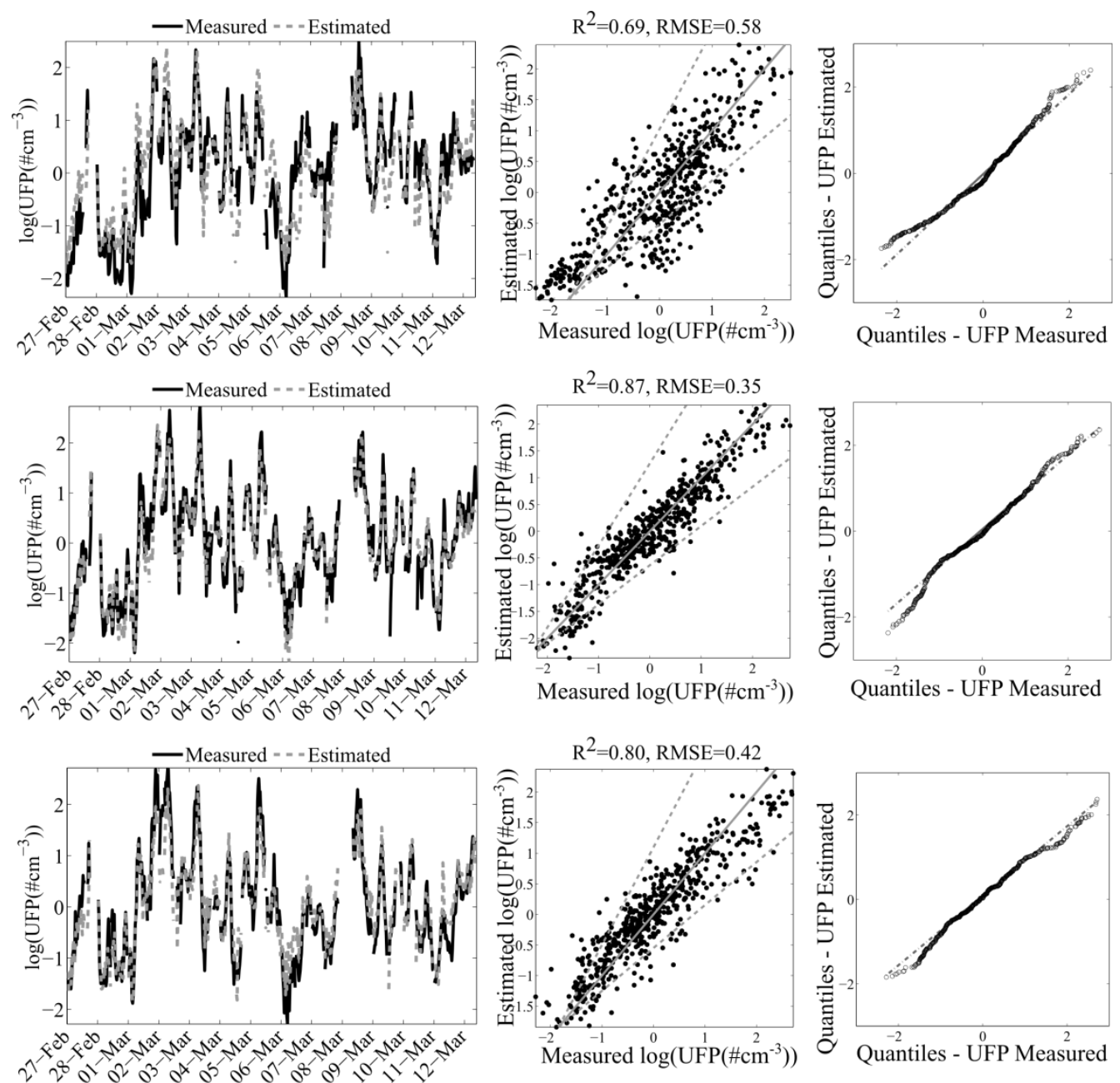

Figure 4: Remote estimation. The left column shows the time series plots of the estimated and the measured UFP number concentrations. The dashed grey line is the estimated UFP number concentration and the black line is the measured UFP number concentration relative to the evaluation period $\left(\mathcal{D}_{\text {eval }}\right)$. The middle column shows the scatterplots, $\mathrm{R}^{2}$ and RMSE between the estimated and measured UFP number concentrations. The grey lines have slope 1 and an intercept of 0 (ideal case, when the estimated and measured values are equal). The dashed grey lines delimit the FAC2 area. The right column shows the QQ plots between the estimated and measured UFP number concentrations. The top row refers to site 1, the middle row refers to site 2 and the bottom row refers to site 3.

Cite this article as: Reggente, M., Peters, J., Theunis, J., Poppel, M.V, Rademaker, M., De Baets, B., Kumar, P., 2015. A comparison of strategies for estimation of ultrafine particle number concentrations in urban air pollution monitoring networks. Environmental Pollution 199, 209-218. Online link: doi:10.1016/j.envpol.2015.01.034 
Tables 4 and 5 also show that the models based on two remote locations are better performing than models based on covariates from one remote location. For example, at sites 1 and 3, the models that use the remote covariates from site 2 have a similar performance as the ones that use the covariates from the other two remote sites simultaneously. On the other hand, at site 1 , the models that use the covariates from site 3 , and at site 3 , the models that use the covariates from site 1, have a weaker performance than the models that use the covariates from two remote sites simultaneously. At site 2 instead, all the models that use covariates from sites 1 or 3 have a weaker performance than the ones that use the covariates from two remote sites simultaneously.

From Figure 4, we can observe that the model tends to overestimate low values of UFP at site 1 and underestimate low values at site 2 .

In summary: (i) model results are comparable when using remote UFP only or when using remote NOx only to estimate UFP at a distant location; (ii) models that use covariates from only one remote site have fair performance only if there is a priori knowledge of which of the two sites is more informative; (iii) models that use covariates from two remote sites do not need apriori knowledge of which of the two sites is more informative because the models learn at which covariate to give more importance during the training period, maximising the likelihood between the covariates and the target function.

\subsubsection{Mixed estimation}

Tables 6 and 7 show the performances of the models for the mixed estimation configuration.

In Table 6 the evaluation refers to models that use local gaseous covariates $\left(\mathrm{NOx}, \mathrm{O}_{3}\right.$ and $\mathrm{CO}$ recorded at the same site where the estimation are made) in addition to UFP concentrations recorded at the other two sites (remote covariates). Table 7 shows the results of cases where only remote NOx (but not UFP) recorded at two sites are added to the local covariates ( $\mathrm{NOx}, \mathrm{O}_{3}, \mathrm{CO}$ ).

Cite this article as: Reggente, M., Peters, J., Theunis, J., Poppel, M.V, Rademaker, M., De Baets, B., Kumar, P., 2015. A comparison of strategies for estimation of ultrafine particle number concentrations in urban air pollution monitoring networks. Environmental Pollution 199, 209-218. Online link: doi:10.1016/j.envpol.2015.01.034 
Comparison of Tables 3-6 shows that the performances of models are improved when the remote UFP are combined with the local gaseous covariates. The best performances (in bold in Table 6) are obtained using the local NOx plus remote UFP; the models explain more than $90 \%$ of the variance at all sites.

The models that combine remote UFP with local $\mathrm{O}_{3}$ or $\mathrm{CO}$ perform better either than the models that use only local $\mathrm{O}_{3}$ and $\mathrm{CO}$ covariates (Table 3) or models based on remote UFP (Table 4).

Table 6: Mixed estimation: evaluation of the models at half hour resolution and 14 days of training in terms of ML, $\mathrm{R}^{2}$ and RMSE. In bold are denoted the models with the highest ML.

\begin{tabular}{|c|c|c|c|c|c|c|c|c|c|}
\hline \multirow[b]{2}{*}{ Target } & \multirow[b]{2}{*}{ Model } & \multirow[t]{2}{*}{$\begin{array}{c}\text { Local } \\
\text { Covariates }\end{array}$} & \multicolumn{3}{|c|}{$\begin{array}{c}\text { Remote } \\
\text { Covariates }\end{array}$} & \multirow[b]{2}{*}{$\mathrm{R}^{2}$} & \multirow[b]{2}{*}{ RMSE } & \multirow[b]{2}{*}{ ML } & \multirow[b]{2}{*}{$\begin{array}{r}\mathcal{D}_{\text {eval }} \\
\text { (days) }\end{array}$} \\
\hline & & & $\begin{array}{l}\text { UFP } \\
\text { Site } 1 \\
\end{array}$ & $\begin{array}{l}\text { UFP } \\
\text { Site } 2 \\
\end{array}$ & $\begin{array}{c}\text { UFP } \\
\text { Site } 3 \\
\end{array}$ & & & & \\
\hline \multirow{3}{*}{$\begin{array}{l}\text { UFP } \\
\text { Site } 1\end{array}$} & $\mathrm{GP}_{\mathrm{S} 1}\left(\mathrm{NOx}_{\mathrm{S} 1}, \mathrm{UFP}_{\mathrm{S} 2}, \mathrm{UFP}_{\mathrm{S} 3}\right)$ & $\mathrm{NO} / \mathrm{NO}_{2}$ & & $\mathbf{X}$ & $\mathbf{X}$ & 0.91 & 0.32 & -114 & 14 \\
\hline & $\mathrm{GP}_{\mathrm{S} 1}\left(\mathrm{O}_{\mathrm{S} 1}, \mathrm{UFP}_{\mathrm{S} 2}, \mathrm{UFP}_{\mathrm{S} 3}\right)$ & & & $\mathrm{X}$ & $\mathrm{X}$ & 0.70 & 0.58 & -282 & 14 \\
\hline & $\mathrm{GP}_{\mathrm{S} 1}\left(\mathrm{CO}_{\mathrm{S} 1}, \mathrm{UFP}_{\mathrm{S} 2}, \mathrm{UFP}_{\mathrm{S} 3}\right)$ & $\mathrm{CO}$ & & $\mathrm{X}$ & $\mathrm{X}$ & 0.77 & 0.50 & -231 & 14 \\
\hline \multirow{2}{*}{$\begin{array}{l}\text { UFP } \\
\text { Site } 2\end{array}$} & $\mathrm{GP}_{\mathrm{S} 2}\left(\mathrm{NOx}_{\mathrm{S} 2}, \mathrm{UFP}_{\mathrm{S} 1}, \mathrm{UFP}_{\mathrm{S} 3}\right)$ & $\mathrm{NO} / \mathrm{NO}_{2}$ & $\mathbf{X}$ & & $\mathbf{X}$ & 0.91 & 0.35 & -69 & 9 \\
\hline & $\mathrm{GP}_{\mathrm{S} 2}\left(\mathrm{O} 3_{\mathrm{S} 2}, \mathrm{UFP}_{\mathrm{S} 1}, \mathrm{UFP}_{\mathrm{S} 3}\right)$ & & $\mathrm{X}$ & & $\mathrm{X}$ & 0.89 & 0.34 & -177 & 9 \\
\hline \multirow{3}{*}{$\begin{array}{l}\text { UFP } \\
\text { Site } 3\end{array}$} & $\mathbf{G P}_{\mathrm{S} 3}\left(\mathrm{NOx}_{\mathrm{S} 3}, \mathrm{UFP}_{\mathrm{S1}}, \mathrm{UFP}_{\mathrm{S} 2}\right)$ & $\mathrm{NO} / \mathrm{NO}_{2}$ & $\mathbf{X}$ & $\mathbf{X}$ & & 0.92 & 0.32 & -265 & 14 \\
\hline & $\mathrm{GP}_{\mathrm{S} 3}\left(\mathrm{O}_{\mathrm{S} 3}, \mathrm{UFP}_{\mathrm{S} 1}, \mathrm{UFP}_{\mathrm{S} 2}\right)$ & & $\mathrm{X}$ & $\mathrm{X}$ & & 0.82 & 0.42 & -404 & 14 \\
\hline & $\mathrm{GP}_{\mathrm{S} 3}\left(\mathrm{CO}_{\mathrm{S} 3}, \mathrm{UFP}_{\mathrm{S} 1}, \mathrm{UFP}_{\mathrm{S} 2}\right)$ & $\mathrm{CO}$ & $\mathrm{X}$ & $\mathrm{X}$ & & 0.80 & 0.50 & -367 & 14 \\
\hline
\end{tabular}

Table 7: Mixed estimation: evaluation of the models at half hour resolution and 14 days of training in terms of ML, $\mathrm{R}^{2}$ and RMSE.

\begin{tabular}{|c|c|c|c|c|c|c|c|c|c|}
\hline Target & Model & $\begin{array}{c}\text { Local } \\
\text { Covariates }\end{array}$ & $\begin{array}{c}\mathrm{NO} / \mathrm{NO}_{2} \\
\text { Site } 1 \\
\end{array}$ & $\begin{array}{c}\text { Remote } \\
\text { Covariates } \\
\mathrm{NO} / \mathrm{NO}_{2} \\
\text { Site } 2 \\
\end{array}$ & $\begin{array}{c}\mathrm{NO} / \mathrm{NO}_{2} \\
\text { Site } 3 \\
\end{array}$ & $\mathrm{R}^{2}$ & RMSE & ML & $\begin{array}{r}\mathcal{D}_{\text {eval }} \\
\text { (days) } \\
\end{array}$ \\
\hline \multirow{3}{*}{$\begin{array}{l}\text { UFP } \\
\text { Site } 1\end{array}$} & $\mathrm{GP}_{\mathrm{S} 1}\left(\mathrm{NOx}_{\mathrm{S} 1}, \mathrm{NOx}_{\mathrm{S} 2}, \mathrm{NOx}_{\mathrm{S} 3}\right)$ & $\mathrm{NO} / \mathrm{NO}_{2}$ & & $\mathrm{X}$ & $\mathrm{X}$ & 0.91 & 0.35 & -136 & 9 \\
\hline & $\mathrm{GP}_{\mathrm{S} 1}\left(\mathrm{O}_{\mathrm{S}_{1},}, \mathrm{NOx}_{\mathrm{S} 2}, \mathrm{NOx}_{\mathrm{S} 3}\right)$ & $\mathrm{O}_{3}$ & & $\mathrm{X}$ & $\mathrm{X}$ & 0.74 & 0.62 & -340 & 9 \\
\hline & $\mathrm{GP}_{\mathrm{S} 1}\left(\mathrm{CO}_{\mathrm{s} 1}, \mathrm{NOx}_{\mathrm{S} 2}, \mathrm{NOx}_{\mathrm{S} 3}\right)$ & $\mathrm{CO}$ & & $\mathrm{X}$ & $\mathrm{X}$ & 0.81 & 0.53 & -299 & 9 \\
\hline \multirow{2}{*}{$\begin{array}{l}\text { UFP } \\
\text { Site } 2\end{array}$} & $\mathrm{GP}_{\mathrm{S} 2}\left(\mathrm{NOx}_{\mathrm{s} 2}, \mathrm{NOx}_{\mathrm{s} 1}, \mathrm{NOx}_{\mathrm{s} 3}\right)$ & $\mathrm{NO} / \mathrm{NO}_{2}$ & $\mathrm{X}$ & & $\mathrm{X}$ & 0.84 & 0.42 & -188 & 9 \\
\hline & $\mathrm{GP}_{\mathrm{S} 2}\left(\mathrm{O} 3_{\mathrm{s} 2}, \mathrm{NOx}_{\mathrm{S} 1}, \mathrm{NOx}_{\mathrm{S} 3}\right)$ & $\mathrm{O}_{3}$ & $\mathrm{X}$ & & $\mathrm{X}$ & 0.80 & 0.48 & -275 & 9 \\
\hline \multirow{3}{*}{$\begin{array}{l}\text { UFP } \\
\text { Site } 3\end{array}$} & $\mathrm{GP}_{\mathrm{S} 3}\left(\mathrm{NOx}_{\mathrm{S} 3}, \mathrm{NOx}_{\mathrm{s} 1}, \mathrm{NOx}_{\mathrm{S} 2}\right)$ & $\mathrm{NO} / \mathrm{NO}_{2}$ & $\mathrm{X}$ & $\mathrm{X}$ & & 0.89 & 0.39 & -332 & 9 \\
\hline & $\mathrm{GP}_{\mathrm{S} 3}\left(\mathrm{O}_{3} 3, \mathrm{NOx}_{\mathrm{S} 1}, \mathrm{NOx}_{\mathrm{S} 2}\right)$ & $\mathrm{O}_{3}$ & $\mathrm{X}$ & $\mathrm{X}$ & & 0.82 & 0.44 & -411 & 9 \\
\hline & $\mathrm{GP}_{\mathrm{S} 3}\left(\mathrm{CO}_{\mathrm{S} 3}, \mathrm{NOx}_{\mathrm{S} 1}, \mathrm{NOx}_{\mathrm{S} 2}\right)$ & $\mathrm{CO}$ & $\mathrm{X}$ & $\mathrm{X}$ & & 0.80 & 0.50 & -412 & 9 \\
\hline
\end{tabular}

Comparison between Tables 3 and 7 shows that the models that use NOx measurements from all the sites have similar performances compared to the models that use only the local covariates. In Cite this article as: Reggente, M., Peters, J., Theunis, J., Poppel, M.V, Rademaker, M., De Baets, B., Kumar, P., 2015. A comparison of strategies for estimation of ultrafine particle number concentrations in urban air pollution monitoring networks. Environmental Pollution 199, 209-218. Online link: doi:10.1016/j.envpol.2015.01.034 
other words, the remote NOx measurements are not improving the estimations based on local gaseous components only. On the other hand, comparing Tables 3, 5 and 7, we note that models that combine remote $\mathrm{NOx}$ with local $\mathrm{O}_{3}$ and $\mathrm{CO}$ perform better either than models that use local $\mathrm{O}_{3}$ and $\mathrm{CO}$ or models based on remote $\mathrm{NOx}$.

From Figure 5, we can observe that the model tends to underestimate low and high values of UFP at site 2. However, these deviations are not substantial, and the estimated distributions seem to describe the measurements well.

In summary: (i) the addition of remote UFP to local NOx results in improved model performance; (ii) the addition of remote NOx to local NOx does not improve the estimation based on local NOx measurements; (iii) the addition of remote UFP or NOx to local $\mathrm{O}_{3}$ or $\mathrm{CO}$ results in improved estimations compared to models that use only local $\mathrm{O}_{3}$ or $\mathrm{CO}$ measurements.

\subsection{Training length}

In practical situations such as designing the measurement campaign and planning the facilities needed, it is useful to know how the model performs according to the amount of data used for training. In Figure 6, the model performance for each site and for each monitoring strategy is evaluated on different days of training at 30 min resolution (solid lines). One day of training refers to the day before the first day of evaluation, two days of training means two days before the first day of evaluation and so on up to 14 days.

The plots show that the performance of models increases with the training length. It seems that a training period of at least seven days (in which at least two days correspond to weekend days) is suitable (in terms of a trade-off between costs and model performance) to let the model learn the UFP dynamics in different typologies of traffic.

Cite this article as: Reggente, M., Peters, J., Theunis, J., Poppel, M.V, Rademaker, M., De Baets, B., Kumar, P., 2015. A comparison of strategies for estimation of ultrafine particle number concentrations in urban air pollution monitoring networks. Environmental Pollution 199, 209-218. Online link: doi:10.1016/j.envpol.2015.01.034 

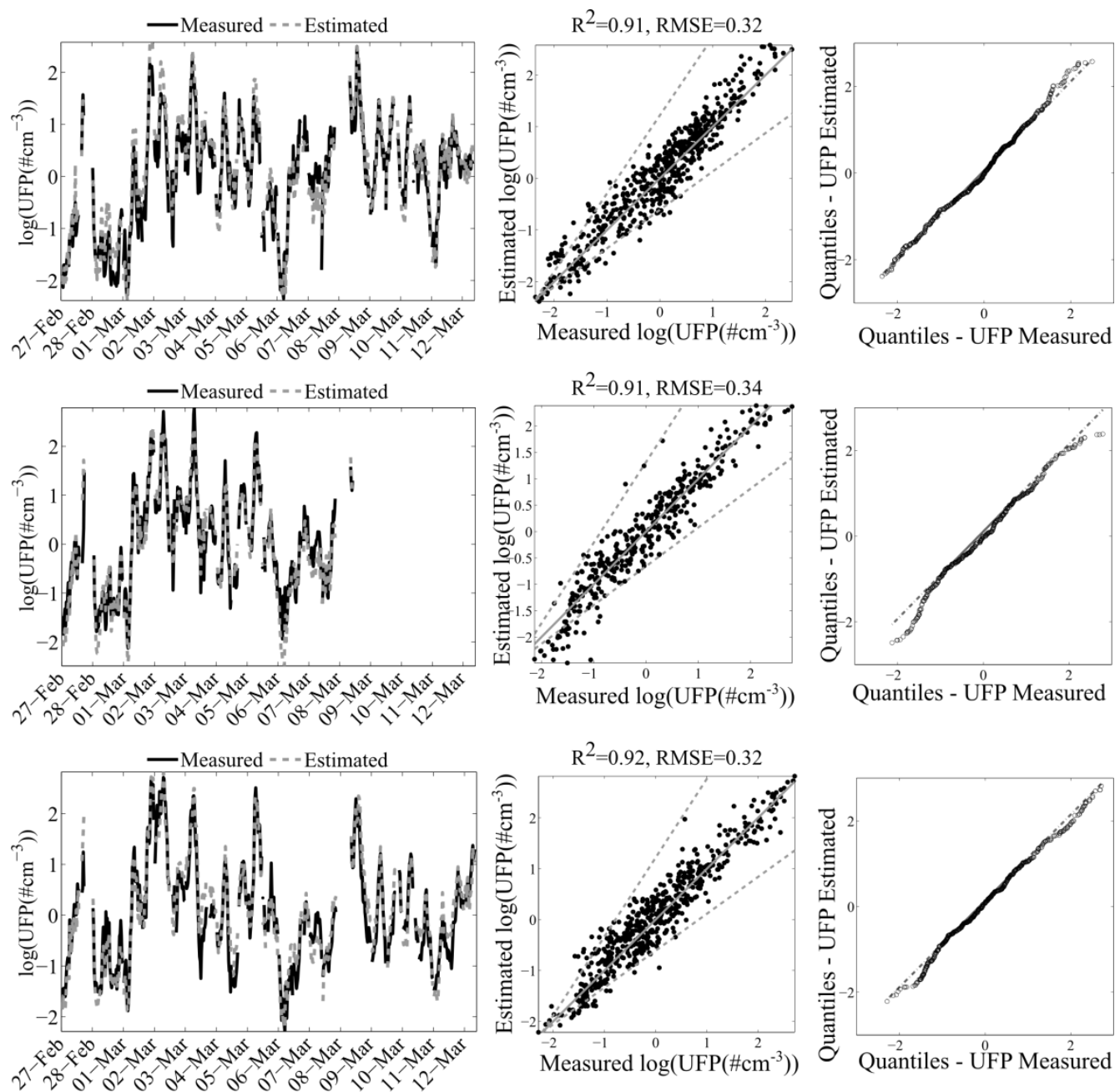

Figure 5: Mixed estimation. The left column shows the time series plots of the estimated and the measured UFP number concentrations. The dashed grey line is the estimated UFP number concentration and the black line is the measured UFP number concentration relative to the evaluation period $\left(\mathcal{D}_{\text {eval }}\right)$. The middle column shows the scatterplots, $\mathrm{R}^{2}$ and RMSE between the estimated and measured UFP number concentrations. The grey lines have slope 1 and an intercept of 0 (ideal case, when the estimated and measured values are equal). The dashed grey lines delimit the FAC2 area. The right column shows the QQ plots between the estimated and measured UFP number concentrations. The top row refers to site 1, the middle row refers to site 2 and the bottom row refers to site 3 .

Cite this article as: Reggente, M., Peters, J., Theunis, J., Poppel, M.V, Rademaker, M., De Baets, B., Kumar, P., 2015. A comparison of strategies for estimation of ultrafine particle number concentrations in urban air pollution monitoring networks. Environmental Pollution 199, 209-218. Online link: doi:10.1016/j.envpol.2015.01.034 


\subsection{Models at 5 min resolution}

All the above results are based on half hour resolution. Considering the high variability of UFP, it is also interesting to have models with a higher time resolution. In Figure 6, the performances of models for each site and for each monitoring strategy are evaluated on different days of training for models at 5 min resolution (dashed lines). The results of these models, as for the half hour models, show a good correspondence of the modelled UFP values with the measured values. Furthermore, the local and mixed estimation models explain up to $85 \%$ of the variance, and the remote estimation around $60 \%$, at site 1 . At site 2 , the mixed estimation model explains up $85 \%$ of the variance, and the local and remote models up to $78 \%$ of the variance. At site 3 , the mixed estimation model explains up to $90 \%$ of the variance, the local estimation model explains up to $86 \%$ of the variance and the remote estimation model explains up to $72 \%$ of the variance.

\subsection{Network complexity}

The three estimation strategies have different levels of complexity. In the local estimation, at the estimation site, this strategy requires the presence of the local covariate monitors or sensors (e.g. NOx) for the whole period (training and estimation), plus the UFP monitor for the training period. The remote estimation strategy requires local UFP for the training, and remote NOx or UFP for the training and estimation periods. The mixed estimation requires UFP data at the estimation site for the training period, plus local NOx and remote UFP or NOx data for the training and estimation periods. This is, however, a costly solution, compared with the local estimation case, given the number of monitoring devices needed and a rather limited increase in estimation accuracy.

Cite this article as: Reggente, M., Peters, J., Theunis, J., Poppel, M.V, Rademaker, M., De Baets, B., Kumar, P., 2015. A comparison of strategies for estimation of ultrafine particle number concentrations in urban air pollution monitoring networks. Environmental Pollution 199, 209-218. Online link: doi:10.1016/j.envpol.2015.01.034 


\begin{tabular}{|c|c|c|}
\hline $\begin{array}{l}\rightarrow \text { Local } 30 \mathrm{~min} \\
-\bullet-\text { Local } 5 \mathrm{~min}\end{array}$ & $\begin{array}{l}=\text { Remote } 30 \mathrm{~min} \\
=- \text { - Remote } 5 \mathrm{~min}\end{array}$ & $\begin{array}{l}- \text { - Mixed } 30 \mathrm{~min} \\
=- \text { Mixed } 5 \text { min }\end{array}$ \\
\hline
\end{tabular}

Site 1
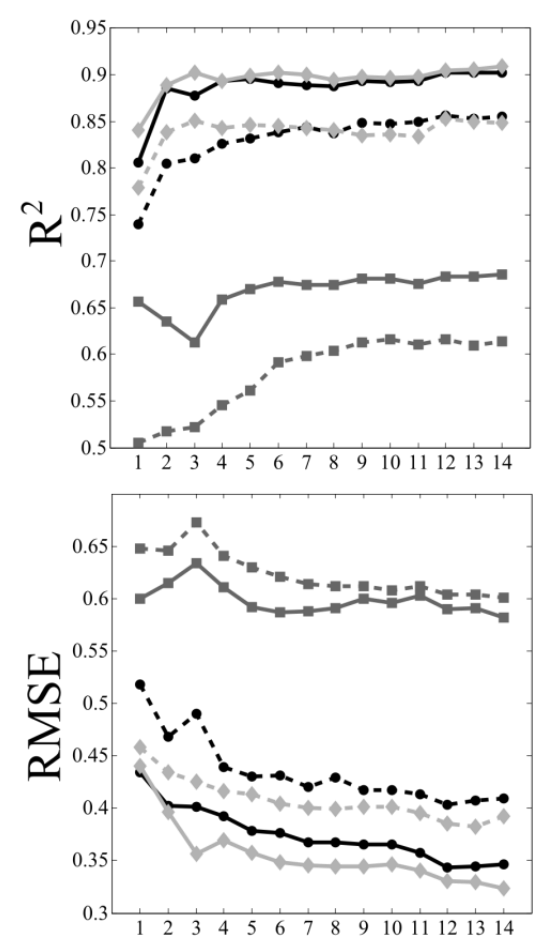

Day of Training
Site 2
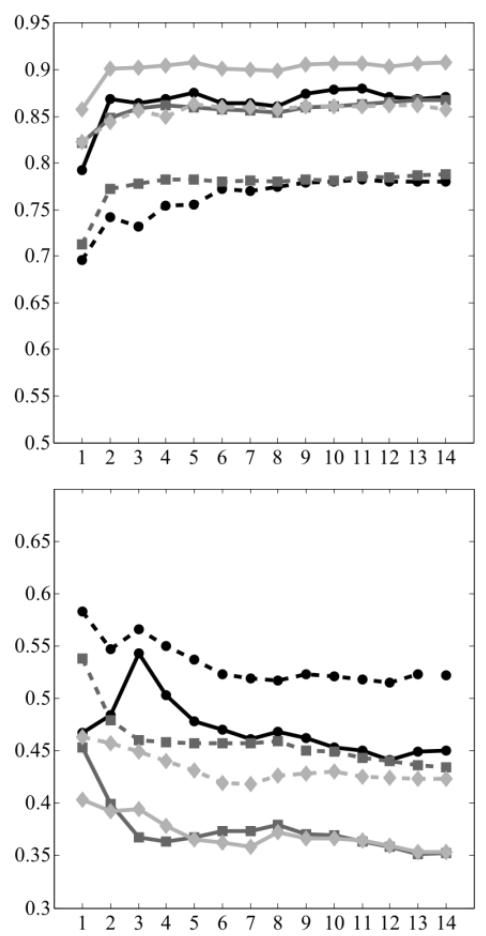

Day of Training
Site 3
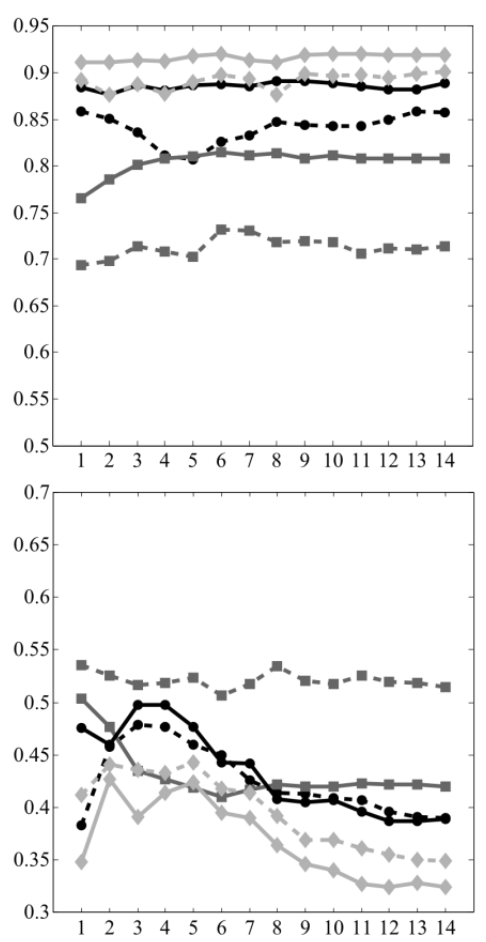

Day of Training

Figure 6: Performances of the GP models at half hour (solid lines) and 5 min (dashed lines) resolution evaluated on different days of training. First row: coefficient of determination $\left(\mathrm{R}^{2}\right)$; second row: root mean square error (RMSE). First column refers to site 1, middle column refers to site 2 and the right column refers to site 3 . One day of training refers to the day before the first day of evaluation, two days of training means two days before the first day of evaluation and so on up to 14 days.

\subsection{Limitations}

The applied modelling approach also has its limitations. For instance, there is no guarantee that the proposed model structure is optimal. However, different covariates (e.g. traffic and 
meteorological data) could be easily added to the proposed structure. For instance, considering that the rain influences the concentrations of gaseous pollutants and UFP differently, models that include weather conditions may have better performances.

The models are developed and trained in the first place for use in traffic locations within city boundaries. All three locations in this study are urban traffic locations, and their pollution profile is dominated by traffic emissions. The three locations are distinct from each other in terms of traffic intensity, distance to traffic and surrounding street pattern. We have tested the method simultaneously at these three different traffic locations, and results were found to be encouraging. Therefore, we assume that the proposed method could be applied to other traffic locations to address part of the spatial inhomogeneity of UFP between sites within a city reported in literature (Mejia et al. 2008; Buonanno et al., 2011; Mishra et al., 2012; Birmili et al., 2013; Kumar et al. 2014). However, this assumption could not be tested with the available data set. Moreover, this study cannot assess how models trained at one area/city perform in other areas/cities with different fleet composition, traffic dynamics and meteorological circumstances. The transferability of these models to other areas is probably limited when circumstances differ substantially. In that case, a new data collection period should be carried out for model training. A further limitation of the used data set is that it is only one month long, and considering that half of it has been used for training, only half a month was left for the evaluation. This restricted the possibility to assess questions such as how long the proposed model will perform satisfactorily, and how often the training has to be performed.

The measurements used in this study were performed during a winter when the influence of photochemical reactions is rather limited. Considering that ratios of $\mathrm{NO}-\mathrm{NO}_{2}-\mathrm{O}_{3}$ are strongly influenced by photochemistry, and secondary formation of UFP is partially driven by

Cite this article as: Reggente, M., Peters, J., Theunis, J., Poppel, M.V, Rademaker, M., De Baets, B., Kumar, P., 2015. A comparison of strategies for estimation of ultrafine particle number concentrations in urban air pollution monitoring networks. Environmental Pollution 199, 209-218. Online link: doi:10.1016/j.envpol.2015.01.034 
atmospheric photochemical reactions and conversion (Westerdahl et al., 2005; Seinfeld and Pandis, 2006), it could be interesting to study their long-term performances by applying the proposed models on data sets that cover various seasons.

Finally, the lower cut-off limit of UFP used here does not account for the nucleation mode particles that are volatile and much more dynamic. It would be interesting to use the model on such data set to evaluate its performance.

\section{Summary and conclusions}

In this work, we investigated strategies to estimate UFP at specific locations based on concentrations of gaseous components at the same and remote locations, and/or UFP at remote locations. We have used Gaussian process regression to estimate UFP at three sites in an air pollution monitoring network.

In the local estimation, we found that the models that use NOx have the best performances. This strategy would be especially interesting in case a dense network of low-cost gas sensors can be deployed: novel low-cost gas sensors are being developed with increasing level of performance (Mead et al., 2013, Kumar et al., 2015).

The case of the remote estimation reflects the situation where one tries to estimate UFP in locations where no local measurements are available. We used the measurements from two locations to estimate UFP at a third location. On a practical level this corresponds to the installation of permanent monitoring devices at two locations, and training the models at all similar locations of interest. The results also suggest that it is possible to estimate UFP at one location based on measurements of NOx at two remote locations. This would give rise to the possibility to install a limited number of NOx monitors at specific locations to estimate UFP at all similar locations in the same city.

Cite this article as: Reggente, M., Peters, J., Theunis, J., Poppel, M.V, Rademaker, M., De Baets, B., Kumar, P., 2015. A comparison of strategies for estimation of ultrafine particle number concentrations in urban air pollution monitoring networks. Environmental Pollution 199, 209-218. Online link: doi:10.1016/j.envpol.2015.01.034 
The case of the mixed estimation examines combinations of remote and local measurements to improve the model performance. This strategy requires the highest number of monitoring devices, and thus presents a trade-off between higher accuracy and increased costs. In practical terms we can conclude that estimations based on remote UFP are improved by adding local covariates to take into account local variability.

\section{Acknowledgement}

This research is part of the IDEA (Intelligent, Distributed Environmental Assessment) project, financially supported by IWT-Vlaanderen (IWT-SBO 080054). The authors thank Carl Rasmussen and Hannes Nickisch for making the GPML Toolbox available.

\section{References}

Alvarez R, Weilenmann M, Favez, J.Y, 2008. Evidence of increased mass fraction of $\mathrm{NO}_{2}$ within real-world NOx emissions of modern light vehicles - derived from a reliable online measuring method. Atmospheric Environment 42, 4699-4707.

Atkinson R.W, Fuller G.W, Anderson H.R, Harrison R.M, Armstrong B, 2010. Urban ambient particle metrics and health: a time-series analysis. Epidemiology 21, 501-511.

Beddows D.C.S, Harrison R.M, 2008. Comparison of average particle number emission factors for heavy and light duty vehicles derived from rolling chassis dynamometer and field studies. Atmospheric Environment 42, 7954-7966.

Beckx C, Denys T, Michiels H, 2013. Analysis of the Belgian Car Fleet 2012 - Report for the Flemish, the Walloon and the Brussels Capital Region. Technical Report. VITO.

Bennett N.D, Croke B.F.W, Guariso G, Guillaume J.H.A, Hamilton S.H, Jakeman A.J, MarsiliLibelli S, Newham L.T.H, Norton J.P, Perrin C, Pierce S.A, Robson B, Seppelt R, Voinov 
A.A, Fath B.D, Andreassian V., 2013. Characterising performance of environmental models. Environmental Modelling \& Software 40, 1-20.

Birmili W, Tomsche L, Sonntag A, Opelt C, Weinhold K, Nordmann S, Schmidt, W, 2013. Variability of aerosol particles in the urban atmosphere of Dresden (Germany): effects of spatial scale and particle size. Meteorologische Zeitschrift 22, 195-211.

Bos I, Jacobs L, Nawrot T.S, de Geus B, Torfs R, Int Panis L, Degraeuwe B, Meeusen R, 2011. No exercise-induced increase in serum BDNF after cycling near a major traffic road. Neuroscience Letters 500, 129-132.

Buonanno G, Lall A.A, Stabile L, 2009. Temporal size distribution and concentration of particles near a major highway. Atmospheric Environment 43, 1100-1105.

Buonanno G, Fuoco F.C, Stabile L, 2011. Influential parameters on particle exposure of pedestrians in urban microenvironments. Atmospheric Environment 45, 1434-1443.

Charron A, Harrison R.M, 2003. Primary particle formation from vehicle emissions during exhaust dilution in the roadside atmosphere. Atmospheric Environment 37, 4109-4119.

Clifford S, Low Choy S, Hussein T, Mengersen K, Morawska L, 2011. Using the Generalised Additive Model to model the particle number count of ultrafine particles. Atmospheric Environment 45, 5934-5945.

de Hartog J.J, Hoek G, Peters A, Timonen K.L, Ibald-Mulli A, Brunekreef B, Heinrich J, Tiittanen P, van Wijnen J.H, Kreyling W, Kulmala M, Pekkanen J, 2003. Effects of fine and ultrafine particles on cardiorespiratory symptoms in elderly subjects with coronary heart disease: the ULTRA study. American Journal of Epidemiology 157, 613-623.

Cite this article as: Reggente, M., Peters, J., Theunis, J., Poppel, M.V, Rademaker, M., De Baets, B., Kumar, P., 2015. A comparison of strategies for estimation of ultrafine particle number concentrations in urban air pollution monitoring networks. Environmental Pollution 199, 209-218. Online link: doi:10.1016/j.envpol.2015.01.034 
Fujitani Y, Kumar P, Tamura K, Fushimi A, Hasegawa S, Takahashi K, Tanabe K, Kobayashi S, Hirano S, 2012. Seasonal differences of the atmospheric particle size distribution in a metropolitan area in Japan. Science of The Total Environment 437, 339-347.

Goel A, Kumar P, 2014. A review of fundamental drivers governing the emissions, dispersion and exposure to vehicle-emitted nanoparticles at signalised traffic intersections. Atmospheric Environment 97, 316-331.

Harrison R.M, Beddows D.C.S, Dall'Osto M, 2011. PMF analysis of wide-range particle size spectra collected on a major highway. Environmental Science \& Technology 45, 5522-5528.

Heal M.R., Kumar P, Harrison R.M, 2012. Particles, air quality, policy and health. Chemical Society Reviews 41, 6606-6630.

Higdon D, 1998. A process-convolution approach to modelling temperatures in the North Atlantic Ocean. Environmental and Ecological Statistics 5, 173-190.

Holmes N.S, Morawska L, 2006. A review of dispersion modelling and its application to the dispersion of particles: An overview of different dispersion models available. Atmospheric Environment 40, 5902-5928.

Hong Y.C, Lee J.T, Kim H, Ha E.H, Schwartz J, Christiani D.C, 2002. Effects of air pollutants on acute stroke mortality. Environmental Health Perspectives 110, 187-191.

Hussein T, Karppinen A, Kukkonen J, Härkönen J, Aalto P.P, Hämeri K, Kerminen V.M, Kulmala M, 2006. Meteorological dependence of size-fractionated number concentrations of urban aerosol particles. Atmospheric Environment 40, 1427-1440.

Jacobs L, Nawrot T.S, de Geus B, Meeusen R, Degraeuwe B, Bernard A, Sughis M, Nemery B, Int Panis L, 2010. Subclinical responses in healthy cyclists briefly exposed to traffic-related air pollution: an intervention study. Environmental Health 9, 64-71.

Cite this article as: Reggente, M., Peters, J., Theunis, J., Poppel, M.V, Rademaker, M., De Baets, B., Kumar, P., 2015. A comparison of strategies for estimation of ultrafine particle number concentrations in urban air pollution monitoring networks. Environmental Pollution 199, 209-218. Online link: doi:10.1016/j.envpol.2015.01.034 
Kittelson D.B., 1998. Engines and nanoparticles: a review. Journal of Aerosol Science 29, 575588.

Kittelson D.B, Watts W.F, Johnson J.P, 2004. Nanoparticle emissions on Minnesota highways. Atmospheric Environment 38, 9-19.

Kumar P, Fennell P, Langley D, Britter R, 2008. Pseudo-simultaneous measurements for the vertical variation of coarse, fine and ultrafine particles in an urban street canyon. Atmospheric Environment 42, 4304-4319.

Kumar P, Robins A, Britter R, 2009. Fast response measurements of the dispersion of nanoparticles in a vehicle wake and a street canyon. Atmospheric Environment 43, 61106118.

Kumar P, Robins A, Vardoulakis S, Britter R, 2010. A review of the characteristics of nanoparticles in the urban atmosphere and the prospects for developing regulatory controls. Atmospheric Environment 44, 5035-5052.

Kumar P, Gurjar B.R, Nagpure A.S, Harrison R.M, 2011a. Preliminary estimates of nanoparticle number emissions from road vehicles in megacity Delhi and associated health impacts. Environmental Science \& Technology 45, 5514-5521.

Kumar P, Robins A, Vardoulakis S, Quincey P, 2011b. Technical challenges in tackling regulatory concerns for urban atmospheric nanoparticles. Particuology 9, 566-571.

Kumar P, Imam B, 2013. Footprints of air pollution and changing environment on the sustainability of built infrastructure. Science of The Total Environment 444, 85-101.

Kumar P, Morawska L, Birmili W, Paasonen P, Hu M, Kulmala M, Harrison R.M, Norford L, Britter R, 2014. Ultrafine particles in cities. Environment International 66, 1-10.

Cite this article as: Reggente, M., Peters, J., Theunis, J., Poppel, M.V, Rademaker, M., De Baets, B., Kumar, P., 2015. A comparison of strategies for estimation of ultrafine particle number concentrations in urban air pollution monitoring networks. Environmental Pollution 199, 209-218. Online link: doi:10.1016/j.envpol.2015.01.034 
Kumar P, Morawska L, Martani C, Biskos G, Neophytou M, Di Sabatino S, Bell M, Norford L, Britter R, 2015. The rise of low-cost sensing for managing air pollution in cities. Environment International 75, 199-205.

Mead M.I, Popoola O.A.M, Stewart G.B, Landshoff P, Calleja M, Hayes M, Baldovi J.J, McLeod M.W, Hodgson T.F, Dicks J, Lewis A, Cohen J, Baron R, Saffell J.R, Jones R.L, 2013. The use of electrochemical sensors for monitoring urban air quality in low-cost, highdensity networks. Atmospheric Environment, 70, 186-203.

Mejía J.F, Morawska L, Mengersen K, 2008. Spatial variation in particle number size distributions in a large metropolitan area. Atmospheric Chemistry and Physics, 8, 1127-1138.

Mishra V.K, Kumar P, Van Poppel M, Bleux N, Frijns E, Reggente M, Berghmans P, Int Panis L, Samson R, 2012. Wintertime spatio-temporal variation of ultrafine particles in a Belgian city. Science of The Total Environment 431, 307-313.

Mølgaard B, Hussein T, Corander J, Hämeri K, 2012. Forecasting size-fractionated particle number concentrations in the urban atmosphere. Atmospheric Environment 46, 155-163.

Morawska L, Thomas S, Bofinger N, Wainwright D, Neale D, 1998. Comprehensive characterization of aerosols in a subtropical urban atmosphere: particle size distribution and correlation with gaseous pollutants. Atmospheric Environment 32, 2467-2478.

Morawska L, Ristovski Z, Jayaratne E.R, Keogh D.U, Ling X, 2008. Ambient nano and ultrafine particles from motor vehicle emissions: Characteristics, ambient processing and implications on human exposure. Atmospheric Environment 42, 8113-8138.

Murray-Smith R, Girard A, 2001. Gaussian Process priors with ARMA noise models. Irish Signals and Systems Conference, 147-153.

Cite this article as: Reggente, M., Peters, J., Theunis, J., Poppel, M.V, Rademaker, M., De Baets, B., Kumar, P., 2015. A comparison of strategies for estimation of ultrafine particle number concentrations in urban air pollution monitoring networks. Environmental Pollution 199, 209-218. Online link: doi:10.1016/j.envpol.2015.01.034 
Peters J, Theunis J, Van Poppel M, Berghmans P, 2013. Monitoring $\mathrm{PM}_{10}$ and ultrafine particles in urban environments using mobile measurements. Aerosol and Air Quality Research 13, $509-522$.

Pey J, Querol X, Alastuey A, Rodríguez S, Putaud J.P, Van Dingenen R, 2009. Source apportionment of urban fine and ultra-fine particle number concentration in a Western Mediterranean city. Atmospheric Environment 43, 4407-4415.

Rasmussen C.E, Ghahramani Z, 2002. Infinite mixtures of Gaussian process experts. Advances in Neural Information Processing Systems 14, MIT Press, 881-888.

Rasmussen C.E, Williams C.K.I, 2006. Gaussian Processes for Machine Learning. MIT Press. Available free of charge at http://www.gaussianprocess.org

Reggente M, Peters J, Theunis J, Van Poppel M, Rademaker M, Kumar P, De Baets B, 2014. Prediction of ultrafine particle number concentrations in urban environments by means of Gaussian process regression based on measurements of oxides of nitrogen. Environmental Modelling \& Software 61, 135-150.

Sabaliauskas K, Jeong C.H, Yao X, Jun Y.S, Jadidian P, Evans G.J, 2012. Five-year roadside measurements of ultrafine particles in a major Canadian city. Atmospheric Environment 49, $245-256$.

Seinfeld J.H. and Pandis S.P, 2006. Atmospheric Chemistry and Physics: From Air Pollution to Climate Change, 2nd Edition, Wiley, Hoboken, New Jersey.

Snelson E, Ghahramani Z, 2006. Sparse Gaussian processes using pseudo-inputs. Advances in Neural Information Processing Systems 18, MIT press, 1257-1264.

Cite this article as: Reggente, M., Peters, J., Theunis, J., Poppel, M.V, Rademaker, M., De Baets, B., Kumar, P., 2015. A comparison of strategies for estimation of ultrafine particle number concentrations in urban air pollution monitoring networks. Environmental Pollution 199, 209-218. Online link: doi:10.1016/j.envpol.2015.01.034 
Westerdahl D, Fruin S, Sax T, Fine P.M, and Sioutas C, 2005. Mobile Platform Measurements of Ultrafine Particles and Associated Pollutant Concentrations on Freeways and Residential Streets in Los Angeles. Atmospheric Environment 41, 3597-3610.

Westmoreland E.J, Carslaw N, Carslaw D.C, Gillah A, Bates E, 2007. Analysis of air quality within a street canyon using statistical and dispersion modelling techniques. Atmospheric Environment 41, 9195-9205. 